\title{
Differential long-term dietary regulation of adipokines, ghrelin, or corticosterone: impact on adiposity
}

\author{
Bernard Beck $^{1,2}$ and Sébastien Richy ${ }^{2}$ \\ ${ }^{1}$ INSERM, U724, Faculté de Médecine, BP 184 F 54505 Vandœuvre-les-Nancy, France \\ ${ }^{2}$ Université Henri Poincaré, EA 3453, Systèmes Neuromodulateurs des Comportements Ingestifs Nancy, 54000 Nancy, France \\ (Correspondence should be addressed to B Beck; Email: bernard.beck@nancy.inserm.fr)
}

\begin{abstract}
In the present experiment, we examined in Long-Evans rats the long-term effects of diets that differed in the energy provided by proteins $(\mathrm{P})$ and fats $(\mathrm{F})$ but provided a constant level of energy from carbohydrates $(55 \%)$ on various hormones regulating feeding and metabolism. Sixty adult rats were fed for 2 months either a high-fat (protein-to-fat, $\mathrm{PF}$ 5/40), a control (PF 15/30), low-fat (PF 30/15), or highprotein (PF 40/5) diet ad libitum. Both the PF 30/15 and the PF 40/5 rats ate significantly less than their PF 5/40 and PF $15 / 30$ counterparts throughout the experiment $(P<0 \cdot 001)$. PF $40 / 5$ rats weighed less than PF $15 / 30$ rats $(P L=0 \cdot 04)$. PF $40 / 5$ and PF 30/15 rats had smaller epididymal and perirenal adipose tissue depots than PF 5/40 and PF 15/30 rats $(P<0.05$ or less $)$. Adiponectin $(+25-47 \%)$ and leptin levels
\end{abstract}

in the PF 5/40 rats were higher than in the three other groups $(P<0.0025$ or less). Ghrelin concentration in the PF 30/15 group was also higher than in the three other groups $(P<0.001$ versus $\mathrm{PF} 5 / 40 ; P<0.05$ versus $\mathrm{PF} 15 / 30$ and PF 40/5). Corticosterone level was 2 - to $2 \cdot 5$-fold higher in PF $40 / 5$ rats than in the three other groups $(P<0 \cdot 01$ or less). Immunoreactive insulin was not different between the four groups. Our current findings thus show that increases in the protein content resulted in a greater degree of leanness, but at sufficiently high levels, also activated the hypothalamopituitary axis. Ghrelin appeared to be down-regulated by increases in fat content and no obvious signs of insulin resistance were observed in any of the rats under study.

Journal of Endocrinology (2008) 196, 171-179

\section{Introduction}

The macronutrient composition of the diet is a very important factor in the regulation of overall body weight and metabolism. Fats and carbohydrates are primarily considered to be sources of energy stores in either adipose tissue or liver, whereas proteins are considered to supply body-building elements. All three of these macronutrients can modulate feeding behavior in a manner that is mainly dependent upon their physical form, type, and quantity in the ingested diet (Sclafani 1987, Warwick \& Schiffman 1992, Bray et al. 2004, Tome 2004). When combined, fats and carbohydrates augment diet palatability (Sclafani et al. 1996, Levine et al. 2003). High-fat (HF) sweet diets are also energy dense and are generally over consumed in the Western countries (Golay \& Bobbioni 1997, ErlansonAlbertsson 2005). Indeed, long-term ingestion of HF/high-carbohydrate diets often leads to the development of overweight, and also of adiposity and metabolic abnormalities (Levin 2005). On the other hand, ingestion of high-protein (HP) diets leads to weight loss in association with decreased energy intake (Anderson \& Moore 2004, Tome 2004). This is mainly due to the high satiating effects of proteins when compared with fats and carbohydrates (Jen et al. 1985, reviewed in Stubbs 1995,

Reid \& Hetherington 1997). It is perhaps also due to a change in palatability. Accordingly, many types of unbalanced diets that show wide variation in their macronutrient composition have been proposed to decrease body weight in obese people (Golay et al. 1996, Astrup et al. 2004, Klein 2004, LaraCastro \& Garvey 2004, SegalIsaacson et al. 2004, Yancy et al. 2004, Dansinger et al. 2005, McAuley et al. 2005). Some diets have become extremely popular due to their gross effects upon body weight despite the lack of any clinical data showing their long-term impact on either cardiovascular risk or cancer development. Moreover, the classical 'yo-yo' phenomenon, i.e., a regain in body weight after discontinuing the diet is observed with many popular diets, indicating that there is often a low adherence and/or difficulties with maintaining them over a long period.

It is also known that the principal hormonal changes that are associated with each type of dietary macronutrient can have either favorable or adverse effects (Wolever 2003, Johnston et al. 2004, Stern et al. 2004). Development of insulin resistance, and more generally of the metabolic syndrome, have been well studied and the overconsumption of both fats and carbohydrates contributes to this development (Reaven 2005). Diet composition also affects adipose tissue hormones such as leptin (Stricker-Krongrad et al. 1998) 
and adiponectin (Havel 2004, Kadowaki \& Yamauchi 2005). It also modulates gastric hormones involved in feeding regulation like ghrelin (Beck et al. 2002, Erdmann et al. 2003, Greenman et al. 2004, Moesgaard et al. 2004, Sanchez et al. 2004, Lindqvist et al. 2005, Pavlatos et al. 2005).

Corticosterone (CORT), which is another important metabolic hormone that is linked to stress situations, is also sensitive to diet composition (Rabolli \& Martin 1977, Devenport et al. 1991). Due to the highly variable diet compositions used in different studies, however, it is often quite difficult to compare the data of published reports. Hence, in our present long-term experiment in rats, we have established conditions in which the contribution of carbohydrates to energy balance is maintained at a constant $(55 \%$ of total calories) level. We then examined the influence of ingestion of diets with proteins $(\mathrm{P})$ and fats $(\mathrm{F})$ providing different proportions of energy on body weight, feeding, and important metabolic hormones. The relationships between adiposity and these hormones (insulin, adipokines, ghrelin, and CORT) were analyzed.

\section{Materials and Methods}

\section{Animals and protocol}

Sixty male Long-Evans rats body weight (BW) 250-300 g; Centre d'Elevage R Janvier, Le Genest St Isle, France) were used in this experiment. The animals were placed in individual wire cages in an air-conditioned room with an automatic $12 \mathrm{~h}$ light $/ 12 \mathrm{~h}$ darkness cycle (lights on at $0900 \mathrm{~h}$ ). They were fed a standard laboratory chow (A 04, UARVillemoisson sur Orge, France) ad libitum and had tap water to drink for 1 week. During the habituation period to these conditions, the rats ingested about $63 \mathrm{kcal}$ of chow per day.

Then, the rats were randomly distributed into four groups of 15 rats that were fed diets in which the PF energy ratio was symmetrically varied: a HF (PF 5/40), a 'control' (PF 15/30), a low-fat (PF 30/15), or a high-protein (PF 40/5) diet. Therefore, each diet provided $55 \%$ of its energy from carbohydrates in the form of two-thirds starch and onethird sucrose. The PF 15/30 diet was named 'control' by reference to Recommended Dietary Allowances for Humans. The exact composition of the four diets is shown in Table 1.

The rats were fed their respective diets for 2 months and both food intake corrected for occasional spillage and body weight were recorded twice weekly. At the end of the experimental period, the rats were killed by decapitation $3 \mathrm{~h}$ after the beginning of the light period. Food was withdrawn during this 3-h period in order that all animals would be in the same nutritional state. Trunk blood was sampled in tubes containing aprotinin (5000 IU/ml, Iniprol, Laboratoires Choay, Paris, France) and EDTA $(1.2 \mathrm{mg} / \mathrm{ml}$, Merck). In addition, the whole epididymal, perirenal, and abdominal subcutaneous fat depots were sampled and weighed.
Table 1 Composition of the four diets

\begin{tabular}{|c|c|c|c|c|}
\hline & PF 5/40 & PF $15 / 30$ & PF $30 / 15$ & PF $40 / 5$ \\
\hline \multicolumn{5}{|l|}{ Ingredient (g/kg) } \\
\hline Wheat starch & 415 & 388 & 353 & 333 \\
\hline Sucrose & 207 & 194 & 177 & 167 \\
\hline Margarine $^{\mathrm{a}}$ & 245 & 172 & 78 & 25 \\
\hline Casein & 63 & 176 & 322 & 405 \\
\hline Salts $^{\mathrm{b}}$ & 40 & 40 & 40 & 40 \\
\hline Vitamins $^{\mathrm{c}}$ & 10 & 10 & 10 & 10 \\
\hline Cellulose & 20 & 20 & 20 & 20 \\
\hline \multicolumn{5}{|l|}{ Energy (\%) } \\
\hline Carbohydrate & 55 & 55 & 55 & 55 \\
\hline Fat & 40 & 30 & 15 & 5 \\
\hline Protein & 5 & 15 & 30 & 40 \\
\hline PF ratio & $0 \cdot 125$ & $0 \cdot 5$ & 2 & 8 \\
\hline Energy density & $4 \cdot 52$ & $4 \cdot 23$ & $3 \cdot 85$ & $3 \cdot 64$ \\
\hline
\end{tabular}

All diets are supplemented with $2 \%$ methionine.

${ }^{a}$ Margarine was a mixture of saturated and unsaturated fats provided by fish oil, soybean oil, colza oil, and palm oil.

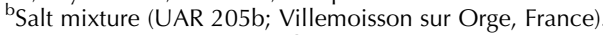

${ }^{\mathrm{C}}$ Vitamin mixture (UAR 200b).

\section{Hormone assays}

Blood samples were centrifuged at $4{ }^{\circ} \mathrm{C}$ for $20 \mathrm{~min}$ and the plasma was distributed in aliquots for the determination of insulin, leptin, adiponectin, CORT, and ghrelin levels. These aliquots were kept at $-20{ }^{\circ} \mathrm{C}$ until assayed.

Plasma glucose and triglycerides were measured by kits using enzymatic methods (BioMérieux, Marcy l'Etoile, France). The hormone levels were measured in duplicate in each case by specific radioimmunoassays using commercially available kits: insulin antibody-coated tubes for immunoreactive insulin (IRI) measurements (Insulin-CT; Cis bio International, Saclay, France) with rat insulin as standard (NOVO, Copenhagen, Denmark), a rat ghrelin kit (RK-031-31; Phoenix Europe GmbH, Karlsruhe, Germany), a rat CORT kit (ICN Pharmaceuticals, Costa Mesa, CA, USA), and a rat leptin kit (RL-83 K; Linco, St Charles, MO, USA). Plasma samples were diluted for the ghrelin assay.

\section{Calculation and statistics}

Different indices were calculated: a food efficiency index was calculated as body weight gain during the experiment (in grams) divided by total food intake in grams or kcal; an adipogenicity index was calculated as weight of the three sampled fat depots divided by total food intake in grams or $\mathrm{kcal}$; an insulin sensitivity index was calculated as plasma glucose $(\mathrm{mmol} / \mathrm{l})$ divided by plasma insulin $(\mathrm{ng} / \mathrm{ml})$. Results are given as the mean \pm s.E.M. and were compared through variance analysis for repeated measures and/or covariance analysis followed by a post hoc protected least significant difference (PLSD) Fisher's test. Energy intake was the covariant when examining the effects of diet type on hormone profile, insulin sensitivity, and adiposity. Regression curves between hormones and either the adiposity or $\mathrm{P} / \mathrm{F}$ 
ratios were also calculated. A probability of 0.05 was considered statistically significant.

\section{Results}

Energy intake, body weight, and adiposity

There was no difference between the four groups in the chow intake during the habituation period. Energy intake variations during the experiment are shown in Fig. 1. Food intake in the four groups followed parallel variations during the experiment and there were significant effects of both diet and time $(P<0.001$ for both). In the four groups, energy intake was elevated during week 1 and was stable from week 2 until the end of the experiment. During week 1, energy intake was $21-23 \%$ greater than the average intake during the following weeks in the PF 5/40, PF 15/30, and PF $30 / 15$ groups $(P<0 \cdot 001)$ and $17 \%$ greater in the PF $40 / 5$ group $(P<0 \cdot 001)$. However, there was a clear separation into two subgroups: one comprising the PF 5/40 and the PF 15/30 rats and the other consisting of the PF 30/15 and the PF 40/5 rats. Both PF 30/15 and $\mathrm{PF} 40 / 5$ rats ingested significantly less energy than the two other groups (cf. Fig. 1) and over the course of the entire experiment, this reduction amounted to about $15 \%$ versus $\mathrm{PF}$ $15 / 30(P<0 \cdot 001)$ and about $12 \%$ versus PF $5 / 40(P<0 \cdot 001)$.

The measured body weight changes are shown in Fig. 2. During our 2-month experiment, all the rats regularly gained weight. There was a significant effect of diet type on body weight $(P<0 \cdot 001)$ with the PF $15 / 30$ rats having a higher body weight than the PF $40 / 5$ rats $(P<0 \cdot 04)$. Body weight gain over the experimental period was also lower in PF 40/5 rats than that in the three other groups $(137.0 \pm 4 \cdot 3 \mathrm{~g}$ versus $154.5 \pm 4.9 \mathrm{~g}(\mathrm{PF} 5 / 40$ rats; $P<0 \cdot 04)$ versus $158 \cdot 9 \pm 6 \cdot 3 \mathrm{~g}$ $(\mathrm{PF} 15 / 30$ rats; $P<0 \cdot 01)$ and versus $153 \cdot 9 \pm 6 \cdot 4 \mathrm{~g}(\mathrm{PF} 30 / 15$ rats; $P<0 \cdot 04)$ ).

Adipose tissue weights are shown in Fig. 3. There was no difference between the adiposity levels of PF 5/40 and PF $15 / 30$ rats regardless of the fat depot applied. PF 30/15 and

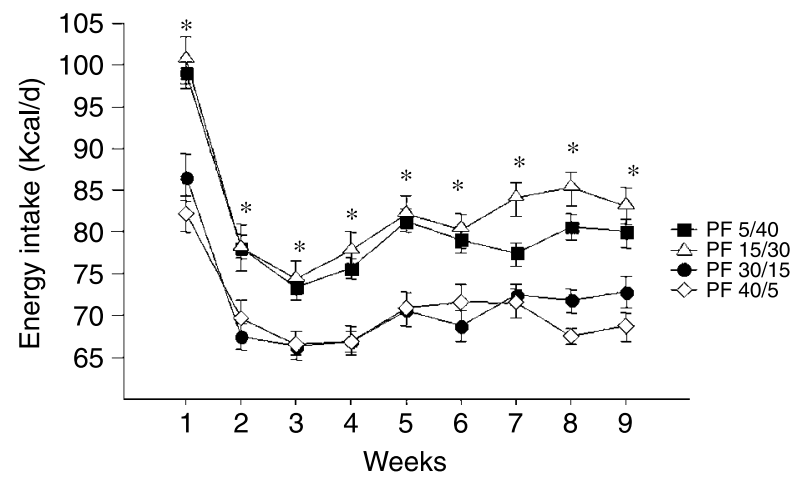

Figure 1 Energy intake (mean \pm S.E.M.) in Long-Evans rats that had been given either a high-fat (PF 5/40), control (PF 15/30), low-fat (PF $30 / 15)$, or high-protein (PF 40/5) diet for 2 months ( $n=15$ per group). ${ }^{*} P<0 \cdot 01$ or less between on one hand PF 5/40 and PF 15/30 rats versus on the other hand PF 30/15 and PF 40/5 rats.

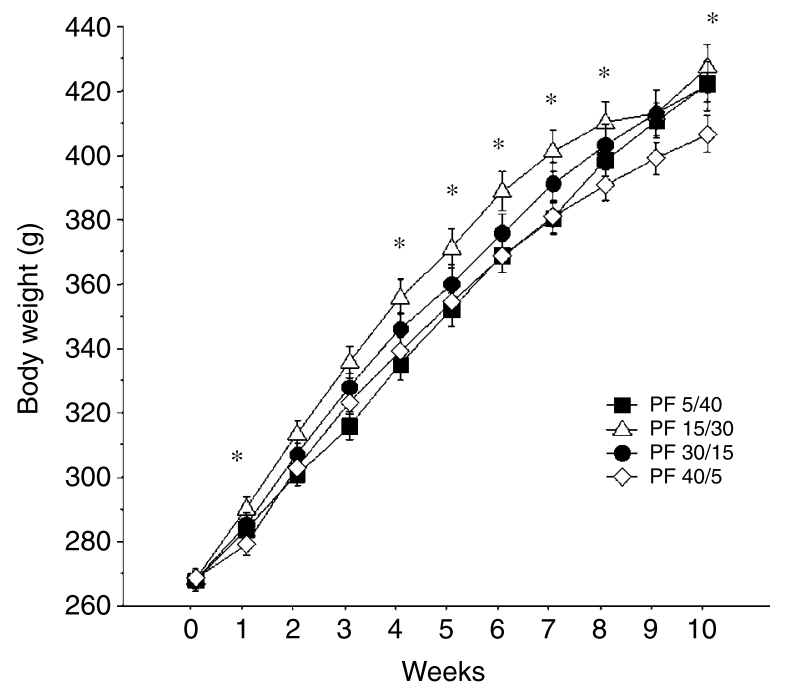

Figure 2 Body weight (mean \pm S.E.M.) in Long-Evans rats that had been given either a high-fat (PF 5/40), control (PF 15/30), low-fat (PF $30 / 15$ ), or high-protein (PF 40/5) diet for 2 months ( $n=15$ per group). ${ }^{*} P<0 \cdot 04$ between PF $15 / 30$ and PF 40/5 rats.

PF 40/5 rats had smaller epididymal and perirenal adipose tissue depots than PF 5/40 and PF 15/30 rats $(P<0 \cdot 02$; cf. Fig. 3). The PF $40 / 5$ rats had also a smaller epididymal fat depot than the PF $30 / 15$ rats $(P<0 \cdot 05)$. The PF $40 / 5$ rats had a smaller abdominal subcutaneous adipose tissue than the $\mathrm{PF}$ $5 / 40$ rats $(P<0 \cdot 005)$ and than the PF $15 / 30$ rats $(P<0 \cdot 003)$.

There was a significant effect of diet type on the food efficiency index expressed per gram of ingested diet $(P<0 \cdot 001)$. The PF $40 / 5$ rats had a significantly lower food efficiency index than the three other groups $(0 \cdot 114 \pm 0 \cdot 004$ vs $0 \cdot 137 \pm 0 \cdot 004(\mathrm{PF} 5 / 40$ rats; $P<0 \cdot 0001)$, versus $0 \cdot 129 \pm$ $0 \cdot 003(\mathrm{PF} 15 / 30$ rats; $P<0 \cdot 01$ ) and versus $0 \cdot 133 \pm 0 \cdot 004$ (PF 30/15 rats; $P<0 \cdot 001)$ ). This effect totally disappeared when the index was expressed by kcal ingested $(P=0 \cdot 20)$. A similar phenomenon was noted for the adipogenicity index, e.g., a significant effect of diet type when the index is expressed per gram of ingested diet $(P<0 \cdot 001)$ with adipogenicity index of PF 40/5 rats lower than that in the three other groups $(P<0 \cdot 02)$ but also a lower index for the PF $30 / 15$ rats versus PF $5 / 40(P<0 \cdot 01)$. Once again, the effect totally disappeared when the adipogenicity index was expressed per kcal ingested $(P=0 \cdot 38)$.

\section{Plasma parameters and hormone profiles}

Plasma glucose and triacylglycerol (TG) levels are shown in Table 2. We found a significant effect of diet type on each parameter $(P<0.005$ for plasma glucose and $P<0.001$ for triglycerides). Plasma glucose levels were not different between PF 5/40 and PF 15/30 rats, but PF 30/15 and PF $40 / 5$ rats had significantly lower plasma glucose concentrations than the PF 5/40 and PF $15 / 30$ groups $(P<0 \cdot 05$; cf. 

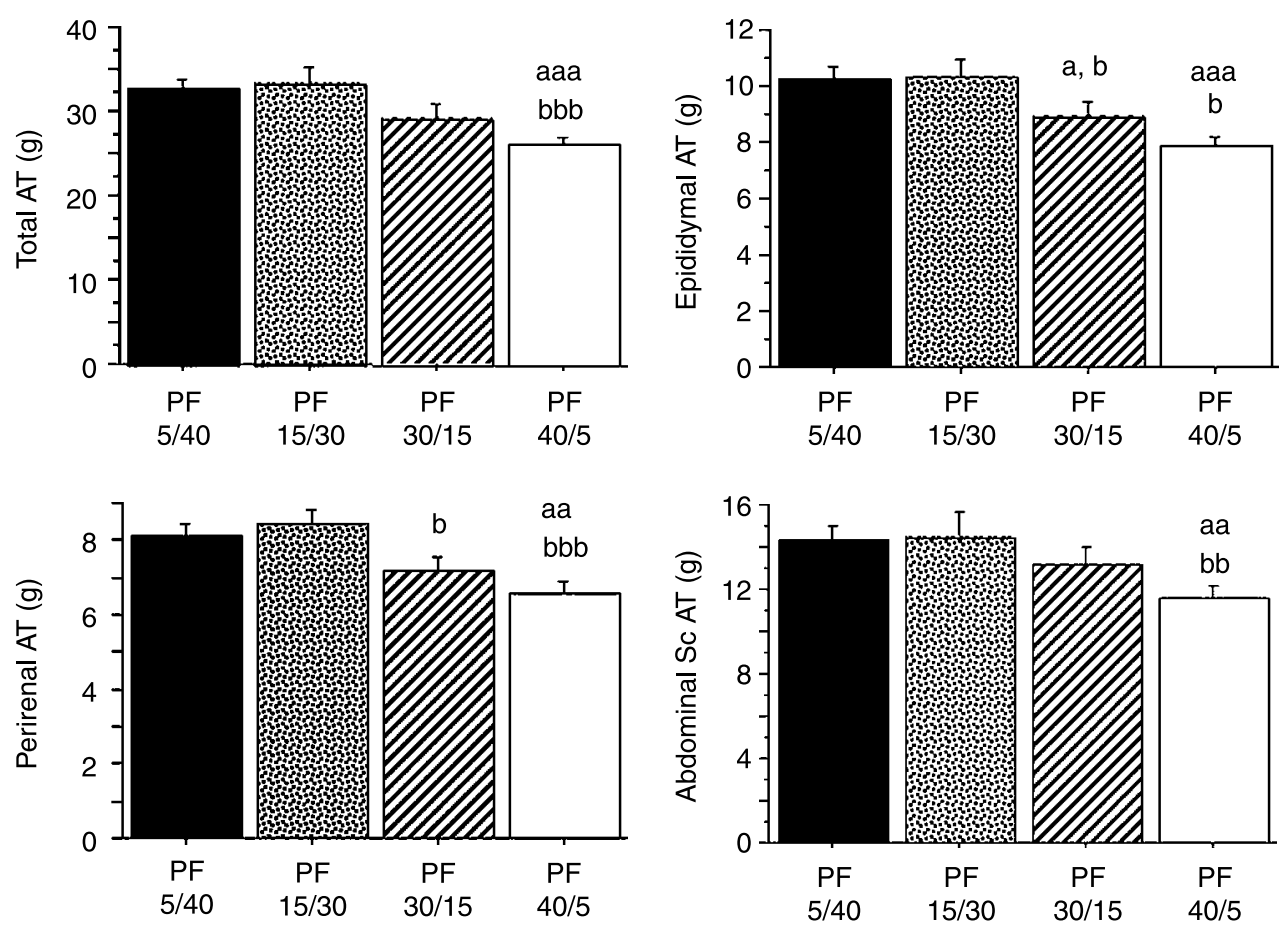

Figure 3 Different fat depot weight measurements (mean \pm S.E.M.) in Long-Evans rats that had been given either a high-fat (PF 5/40), control (PF 15/30), low-fat (PF 30/15), or high-protein (PF 40/5) diet for 2 months ( $n=15$ per group). AT, adipose tissue. ${ }^{a} P<0.05$ versus $P F 5 / 40$ rats; ${ }^{\text {aa }} P<0 \cdot 01$ versus $P F 5 / 40$ rats; ${ }^{\text {aaa }} P<0 \cdot 001$ versus $P F 5 / 40$ rats; ${ }^{b} P<0.05$ versus $P F 15 / 30$ rats; ${ }^{\text {bbb }} P<0.001$ versus $P F 15 / 30$ rats.

Fig. 4). PF $5 / 40$ rats had significantly higher TG concentrations than the three other groups $(P<0 \cdot 005)$.

IRI levels as well as insulin sensitivity index were not significantly different between the four groups (Table 2).

Adipocytokines (leptin and adiponectin), CORT, and ghrelin concentrations are shown in Fig. 4. All four were also influenced by diet type $(P<0 \cdot 0025$ for leptin, $P<0 \cdot 01$ for ghrelin, $P<0.002$ for CORT, and $P<0.001$ for adiponectin). Leptin levels in PF 5/40 rats were significantly higher than that in the three other groups. Leptin production per unit total adipose tissue was significantly higher in PF 5/ 40 rats than that in the three other groups $(0.77 \pm 0.09$ versus $0 \cdot 60 \pm 0 \cdot 11$ (PF 15/30), 0.64 $\pm 0 \cdot 10$ (PF 30/15), $0 \cdot 66 \pm 0 \cdot 03$ (PF 40/5); $P<0 \cdot 025)$. Ghrelin concentration in the PF $30 / 15$ group was significantly higher than in the three other groups
$(P<0 \cdot 001$ versus $\mathrm{PF} 5 / 40 ; P<0 \cdot 05$ versus $\mathrm{PF} 15 / 30$ and PF 40/5).

Adiponectin levels were significantly higher in PF $5 / 40$ rats than that in either PF $15 / 30(+25 \% ; P<0 \cdot 001)$, PF $30 / 15$ $(+40 \% ; P<0 \cdot 001)$, or PF $40 / 5$ rats $(+47 \% ; P<0 \cdot 001)$. In $\mathrm{PF} 15 / 30$ rats, adiponectin level was higher than that in $\mathrm{PF}$ $40 / 5$ rats $(+16 \% ; P<0 \cdot 04)$. CORT concentrations were significantly higher (2- to $2 \cdot 5$-fold) in PF $40 / 5$ rats than that in the three other groups $(P<0 \cdot 001$ versus $P F 5 / 40 ; P<0 \cdot 01$ versus $P F 15 / 30$ and $P<0 \cdot 001$ versus $P F 30 / 15)$.

Relationships between hormone levels, adiposity, and diet composition

Regression curves between the different hormones under study and the fat depot weights as an index of adiposity are

Table 2 Plasma parameters in rats after the ingestion of either a high-fat (protein-to-fat, PF 5/40), a control (PF 15/30), a low-fat (PF 30/15), or a high-protein (PF 40/5) diet for 2 months

\begin{tabular}{|c|c|c|c|c|}
\hline & PF 5/40 & PF 15/30 & PF 30/15 & PF 40/5 \\
\hline $\mathrm{BG}(\mathrm{mmol} / \mathrm{l})$ & $6 \cdot 79 \pm 0 \cdot 08$ & $6 \cdot 70 \pm 0 \cdot 10$ & $6 \cdot 42 \pm 0 \cdot 12^{*, \neq}$ & $6 \cdot 31 \pm 0 \cdot 09^{t, \S}$ \\
\hline IRI (ng/ml) & $9 \cdot 65 \pm 1 \cdot 07$ & $8 \cdot 50 \pm 0 \cdot 74$ & $9 \cdot 60 \pm 0 \cdot 94$ & $8 \cdot 28 \pm 0 \cdot 83$ \\
\hline IRI/BG & $0.79 \pm 0.06$ & $0.89 \pm 0.09$ & $0 \cdot 76 \pm 0 \cdot 08$ & $0 \cdot 87 \pm 0 \cdot 09$ \\
\hline TG (mmol/l) & $4 \cdot 04 \pm 0 \cdot 36$ & $2 \cdot 87 \pm 0 \cdot 32^{+}$ & $2 \cdot 45 \pm 0 \cdot 22^{\dagger}$ & $2 \cdot 25 \pm 0 \cdot 18^{\dagger}$ \\
\hline
\end{tabular}

BG, blood glucose; IRI, immunoreative insulin; TG, triglycerides. ${ }^{*} P<0 \cdot 01$ versus $P F 5 / 40 ;{ }^{\dagger} P<0 \cdot 001$ versus $\mathrm{PF} 5 / 40 ;{ }^{\ddagger} P<0 \cdot 05$ versus $\mathrm{PF} 15 / 30 ;{ }^{\circledR} P<0 \cdot 01$ versus PF $15 / 30$. 

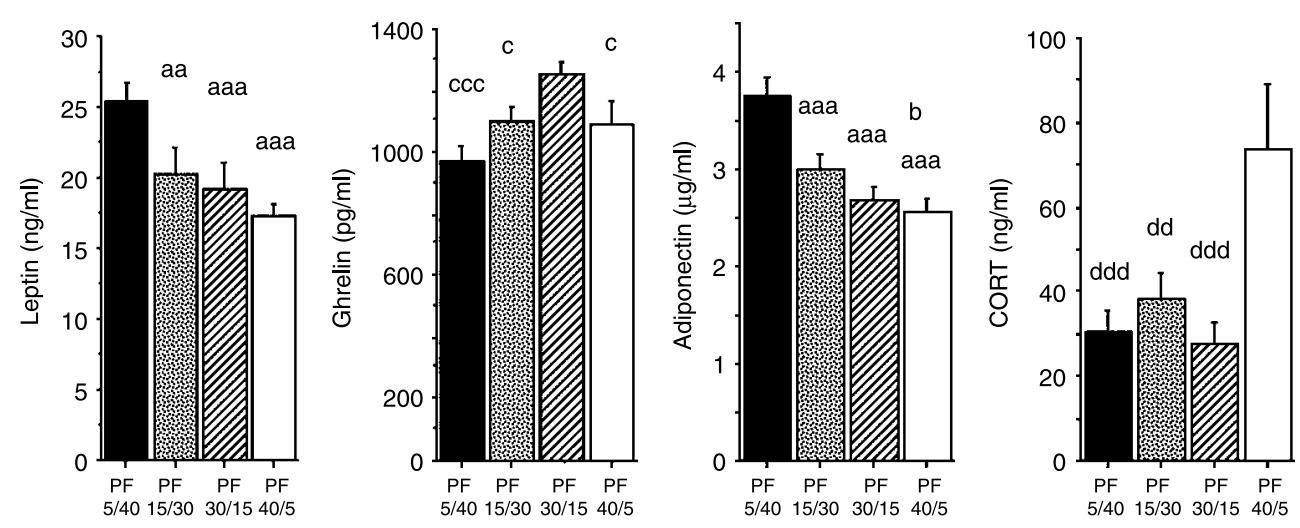

Figure 4 Plasma leptin, ghrelin, adiponectin, and corticosterone (CORT) concentrations (mean \pm s.E.M.) in Long-Evans rats on either a high-fat (PF 5/40), control (PF 15/30), low-fat (PF 30/15), or high-protein (PF 40/5) diet for 2 months ( $n=15$ per group). aa $P<0.01$ versus $P F 5 / 40$ rats; ${ }^{\text {aaa }} P<0.001$ versus $P F 5 / 40$ rats; ${ }^{b} P<0 \cdot 05$ versus $P F \quad 15 / 30$ rats; ${ }^{c} P<0.05$ versus $P F 30 / 15$ rats; ${ }^{c c c} P<0.001$ versus $P F 30 / 15$ rats; ${ }^{\text {dd }} P<0 \cdot 01$ versus $P F$ 40/5 rats; ${ }^{\text {ddd }} P<0 \cdot 001$ versus $P F 40 / 5$ rats.

shown in Fig. 5. There was a strong correlation found between leptin levels and both adiposity $(r=0 \cdot 79$; $P<0 \cdot 0001)$ and final body weight $(r=0 \cdot 69 ; P<0 \cdot 0001)$ as well as between leptin production per unit deep abdominal adipose tissue (epididymal + perirenal) and final body weight $(r=0 \cdot 28 ; P=0 \cdot 03)$. A significant correlation was also observed between adiposity and on the one hand IRI $(r=0 \cdot 54 ; \quad P<0 \cdot 0001)$ and on the other hand adiponectin $(r=0 \cdot 47 ; P<0 \cdot 001)$. In the case of ghrelin, there was a tendency for an inverse correlation $(P<0 \cdot 08)$ with adiposity when calculated for the four groups. This correlation became significant when calculated for the PF $5 / 40$, PF $15 / 30$, and PF $30 / 15$ rats only $(r=-0 \cdot 39$; $P<0 \cdot 01$ ).

There was a negative correlation found between the $\mathrm{P} / \mathrm{F}$ ratio and either leptin $(r=-0 \cdot 35 ; P<0 \cdot 01)$, adiponectin $(r=-0 \cdot 44 ; P<0 \cdot 001)$, or total adipose tissue weight $(r=-0 \cdot 42 ; P<0 \cdot 001)$.
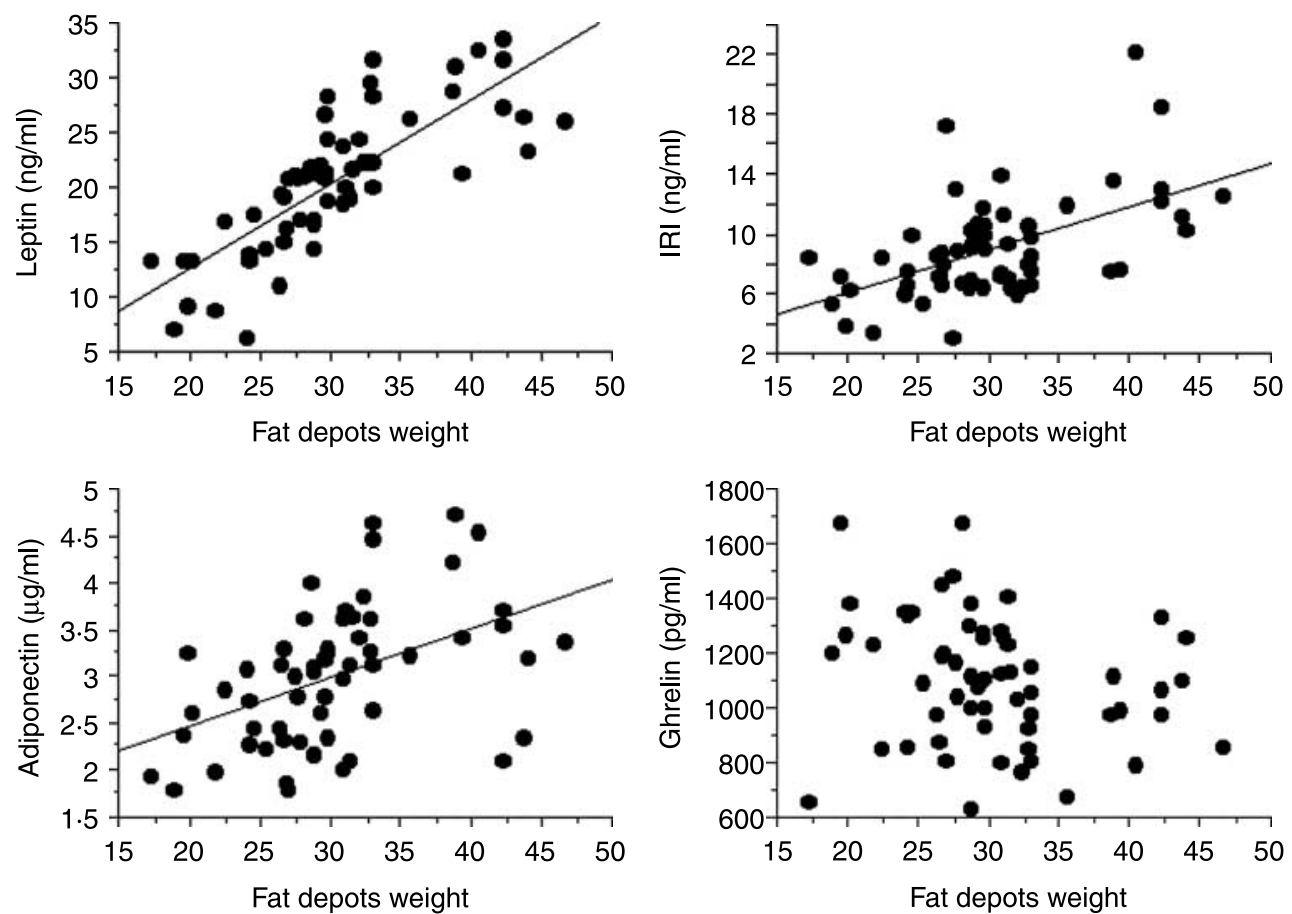

Figure 5 Correlations between total fat depots weight and either plasma leptin, immunoreactive insulin (IRI), adiponectin, or ghrelin concentrations in Long-Evans rats on either a high-fat (PF 5/40), control (PF 15/30), low-fat (PF 30/15), or high-protein (PF 40/5) diet for 2 months. $n=15$ per group. 


\section{Discussion}

Obesity is becoming a worldwide epidemic with the prevalence of obese people increasing rapidly particularly in Western developed countries (James 2004). During the last decade, numerous types of diet that are either low in fat or low in carbohydrates have been recommended in order to induce weight loss in obese people (Bravata et al. 2003, Astrup et al. 2004, LaraCastro \& Garvey 2004, McAuley et al. 2005). More recently, there has been an emphasis on protein-rich diets (Tome 2004, Astrup 2005) but all these diets are associated with energy restriction in order to be more efficient. The goal of our present experiment was to study the metabolic adaptation of normal rats to the long-term ingestion of diets that differed in their protein and fat energy content but provided the same percentage of energy from carbohydrates. The hormonal and metabolic effects obtained at the end of this experiment without food restriction was analyzed in relation with body weight and energy intake variations.

The increased palatability of the four diets versus chow, possibly due at least to the presence of sucrose, likely explains the intake of the four groups during week 1 of the experiment. Nonetheless, the rats ingesting the two protein-rich diets ate less than the two other groups. From week 2, there was a metabolic adaptation to these new diets but the clear dichotomy in energy intake between the PF $40 / 5$ and PF $30 / 15$ groups on one hand and the PF 15/30 and PF 5/40 groups on the other hand remained. The two former groups with the highest level of protein went on to consistently eat less than either the PF $15 / 30$ or PF $5 / 40$ rats. A similar reduction in energy intake has been observed in human when the protein content of the diet is increased (Skov et al. 1999, Due et al. 2004, Weigle et al. 2005). The change of diet palatability due to the higher fat content and to the slightly higher sweetness of the PF $15 / 30$ and PF 5/40 diets could also explain the difference in energy intake with the PF $30 / 15$ and the PF 40/5 rats. All four groups of animals in this study regularly gained weight during the course of the experiment but the PF 40/5 rats gained less weight than the three other groups. Food efficiency in the PF $40 / 5$ rats expressed per calorie ingested was not significantly different and the effect on body weight can therefore be attributed to the lower intake of this group. Changes in intake had much more clear-cut impact upon adiposity levels as a marked reduction in deep abdominal adipose tissue mass was observed in PF 30/15 rats and PF 40/5 rats. A lower effect was also observed for the subcutaneous abdominal adipose tissue. These results confirm previous observations of the effects of high-protein diets on visceral adiposity in human or rats (Due et al. 2004, Lacroix et al. 2004). The differences between PF 30/15 or PF 40/5 rats and the two other groups are also likely to be due to some changes in energy expenditure as thermogenesis is increased by a high-protein diet (Johnston et al. 2002, Halton \& Hu 2004).
The data from our PF 5/40 rats show that the 10\% increase in diet fat content to the detriment of the protein level did not induce any significant change in energy intake when compared with the control rats. This indicates that under conditions of normal carbohydrate availability, rats can rapidly adapt their intake to such relevant changes in the diet composition and control their body weight in a satisfactory manner.

A specific hormonal profile was attached to the phenotype of each dietary group. PF 40/5 and PF 5/40 rats were particularly representative of this phenomenon. In our experiment, PF 40/5 rats had the lowest leptin levels. This is consistent with their lowest adiposity. They differed from the other groups in two respects, their ghrelin and CORT levels. When ghrelin is chronically injected either in the brain or in the periphery, it stimulates food intake and decreases energy expenditure leading to overweight development (Tschop et al. 2000). This hormone is also sensitive to the fat and carbohydrate content of the diet (Beck et al. 2002). Accordingly, we found an inverse correlation between the fat content of the diet and the plasma ghrelin concentrations in the PF 5/40, PF 15/30, and PF 30/15 groups that confirmed some of our previous observations (Beck et al. 2002). The correlation between ghrelin levels and the dietary fat content was no longer evident when the PF 40/5 rats were included in the calculations, thus suggesting that the regulation by ghrelin is either no more functional or less operational when a very low-fat/high-protein content is present in the diet. The threshold is for a $\mathrm{P} / \mathrm{F}$ ratio $>2$. This is in agreement with the persistence of ghrelin at levels that are lower than the baseline for a longer duration following a high-protein (45\%) meal (AlAwar et al. 2005).

In the PF $40 / 5$ rats, the absence of a further augmentation in ghrelin concentrations is likely to be partly due to their high CORT levels. Ghrelin concentration is indeed lower after a prednisolone treatment or exhibits a strong inverse temporal association with serum cortisol in normal subjects (Otto et al. 2004, Espelund et al. 2005). The CORT increase might also contribute cooperatively with ghrelin to some replenishment of energy stores through their combined action in adipose tissue (Tung et al. 2004). So, the PF $40 / 5$ rats might be more susceptible to weight regain after a dietary change by stimulating fat intake through their high CORT status (Bligh et al. 1990, 1993, Prasad et al. 1995). Additionally, CORT increase is also a sign of activation of the hypothalamopituitary axis (HPA). The HPA activation is partly dependent on the macronutrient composition of the diet (Rabolli \& Martin 1977, Devenport et al. 1991). For basal CORT, we did not measure any difference between the PF 5/40 and either PF $15 / 30$ or PF $30 / 15$ rats. These data agree with previous experiments showing the absence of variations in basal CORT levels after exposure to a HF diet (Rabolli \& Martin 1977, Kamara et al. 1998, Legendre \& Harris 2006). However, we cannot exclude a change in sensitivity to stress in the PF 5/40 rats as HF diets augment HPA responsivity to restraint stress with an impact that may vary with the duration 
of exposure to a HF content (Tannenbaum et al. 1997, Kamara et al. 1998, Legendre \& Harris 2006). On the other hand, the presence of sucrose in the diets could have counteracting effects as sucrose or palatable diet ingestion induces a decrease in CORT response to restraint (Strack et al. 1997, Pecoraro et al. 2004) but as HF content, does not alter basal CORT. The high basal CORT measured in the PF 40/5 rats was rather unexpected even if a CORT increase has been observed after a high-protein meal (Gibson et al. 1999). This large increase constitutes a sign of alteration of the HPA axis in the PF 40/5 rats. It is therefore possible that these rats will react differently than the other groups to environmental cues that are either related to nutrition or to other behaviors (e.g., fear, aggressiveness, etc). This is supported, for example, by a greater activity/reactivity of the PF $40 / 5$ rats when opening the cage door for feeding them (personal and non-quantified observations). Ghrelin might contribute to this situation through its anxiogenic effects (Carlini et al. 2002). However, only the measurement of other components of the HPA axis such as central corticotropin-releasing factor in association with different behavioral tests will allow us to confirm this hypothesis in the future.

Our PF 5/40 rats showed the highest levels of leptin that may have served to regulate their food intake near control levels. Their leptin production by unit adipose tissue was also higher and positively associated with final body weight. This confirms several previous findings showing that the leptin system is very sensitive to the fat content of the diet (Ahren et al. 1997, Cooling et al. 1998, Stricker-Krongrad et al. 1998) but not those of Ainslie and colleagues who have shown a negative association between leptin production and body weight in rats fed a moderately HF diet (Ainslie et al. 2000). Diet type and/or rat strain might explain these differences.

The adiponectin levels were paradoxically elevated in the PF $5 / 40$ rats as in rodents; HF diet is associated with insulin resistance and decreased adiponectin (Yamauchi et al. 2001). Our data, however, agree with previous findings in humans showing a positive association between adiponectin and total fat intake (Pischon et al. 2005) and similar variations of adiponectin with the PF ratio have been noted in a recent paper (Morens et al. 2005). This indicates therefore an adaptation to maintain a normal insulin action. This is confirmed by the absence of difference in the insulin sensitivity index that we calculated but the absence of insulin resistance needs, however, to be confirmed by glucose tolerance tests. Maintenance of adequate adiponectin concentration might be related to the low ghrelin levels in PF 5/40 rats. Adiponectin gene expression in adipocytes, which is correlated with plasma levels (DegawaYamauchi et al. 2005), is indeed impaired by chronic exposure to ghrelin (Ott et al. 2002). With a PF ratio of $<2$, ghrelin appeared to be metabolically active and its lower levels might also help to limit energy intake in PF 5/40 rats. The only adverse dietary effect that we noted in PF 5/40 rats concerned the high concentration of plasma triglycerides that may augment the risk of cardiovascular diseases.
Between the two groups with extreme $\mathrm{P} / \mathrm{F}$ ratios, variations in ghrelin concentration in the PF 15/30 and PF 30/15 rats indicate that regulatory mechanisms are functioning in a proper manner in these animals to control fat deposits in PF 15/30 rats and stimulate fat storage in PF 30/15 rats at least through ghrelin. A similar increase in ghrelin secretion has been observed in human and rats when fats were substituted for protein in a way similar to our PF 30/15 rats (VallejoCremades et al. 2004, Weigle et al. 2005). Ghrelin levels, however, are unchanged under dietary conditions in which carbohydrates are substituted for fat and when the protein content is unchanged, e.g., when the diet is switched from $35 \%$ fat $/ 45 \%$ carbohydrates $/ 20 \%$ proteins to $15 \%$ fat $/ 65 \%$ carbohydrates $/ 20 \%$ proteins (Weigle et al. 2003). This is also the case when the switch is between protein and fat at a lower (37\%) level of carbohydrates (Moran et al. 2005). All these observations indicate that each macronutrient plays an important role for ghrelin regulation.

In conclusion, we show from our current experiments that the PF 40/5 diet comprising a normal supply of energy from carbohydrates was the less obesogenic diet of the four diets that were tested in this study. It was, however, the sole diet that we found could be associated with some signs of HPA activation which might have negative effects in the long term. Quite similar positive effects on adiposity were obtained with the PF 30/15 diet which is less extreme in its macronutrient composition. It is interesting to note that in the conditions we used no obvious signs of insulin resistance were observed. Hence, it will now be interesting to combine these diets with some energy restriction in order to assess whether the same type of regulation occurs and whether differences in body weight loss can be obtained in selected obese subjects.

\section{Acknowledgements}

The authors thank Dr C Villaume for his help in bibliographic search, Mrs F Bergerot for her excellent technical assistance, and Mr A Fillion for his help in animal care. These data have been presented under abstract form at the 14th European Congress on Obesity in Athens (Greece). This study was supported by a Research Prize of Institut Benjamin Delessert (Paris). The authors had no conflict of interest to declare.

\section{References}

Ahren B, Mansson S, Gingerich RL \& Havel PJ 1997 Regulation of plasma leptin in mice: Influence of age, high-fat diet, and fasting. American Journal of Physiology 42 R113-R120.

Ainslie DA, Proietto J, Fam BC \& Thorburn AW 2000 Short-term, high-fat diets lower circulating leptin concentrations in rats. American Journal of Clinical Nutrition 71 438-442.

AlAwar R, Obeid O, Hwalla N \& Azar S 2005 Postprandial acylated ghrelin status following fat and protein manipulation of meals in healthy young women. Clinical Science 109 405-411.

Anderson GH \& Moore SE 2004 Dietary proteins in the regulation of food intake and body weight in humans. Journal of Nutrition 134 974S-979S. 
Astrup A 2005 The satiating power of protein - a key to obesity prevention? American Journal of Clinical Nutrition 82 1-2.

Astrup A, Meinert Larsen T \& Harper A 2004 Atkins and other lowcarbohydrate diets: hoax or an effective tool for weight loss? Lancet 364 897-899.

Beck B, Musse N \& Stricker Krongrad A 2002 Ghrelin, macronutrient intake and dietary preferences in Long-Evans rats. Biochemical and Biophysical Research Communications 292 1031-1035.

Bligh ME, Destefano MB, Kramlik SK, Douglass LW, Dubuc P \& Castonguay TW 1990 Adrenal modulation of the enhanced fat intake subsequent to fasting. Physiology and Behavior 48 373-381.

Bligh ME, Douglass LW \& Castonguay TW 1993 Corticosterone modulation of dietary selection patterns. Physiology and Behavior 53 975-982.

Bravata DM, Sanders L, Huang J, Krumholz HM, Olkin I, Gardner CD \& Bravata DM 2003 Efficacy and safety of low-carbohydrate diets - a systematic review. Journal of the American Medical Association 289 1837-1850.

Bray GA, Paeratakul S \& Popkin BM 2004 Dietary fat and obesity: a review of animal, clinical and epidemiological studies. Physiology and Behavior 83 549-555.

Carlini VP, Monzon ME, Varas MM, Cragnolini AB, Schioth HB, Scimonelli TN \& de Barioglio SR 2002 Ghrelin increases anxiety-like behavior and memory retention in rats. Biochemical and Biophysical Research Communications 299 739-743.

Cooling J, Barth J \& Blundell J 1998 The high-fat phenotype: is leptin involved in the adaptive response to a high fat (high energy) diet? International Journal of Obesity 22 1132-1135.

Dansinger ML, Gleason JA, Griffith JL, Selker HP \& Schaefer EJ 2005 Comparison of the Atkins, Ornish, Weight watchers, and Zone diets for weight loss and heart disease risk reduction. Journal of the American Medical Association 293 43-53.

DegawaYamauchi M, Moss KA, Bovenkerk JE, Shankar SS, Morrison CL, Lelliott CJ, VidalPuig A, Jones R \& Considine RV 2005 Regulation of adiponectin expression in human adipocytes: effects of adiposity, glucocorticoids, and tumor necrosis factor alpha. Obesity Research 13 662-669.

Devenport L, Knehans A, Thomas T \& Sundstrom A 1991 Macronutrient intake and utilization by rats: interactions with type I adrenocorticoid receptor stimulation. American Journal of Physiology 260 R73-R81.

Due A, Toubro S, Skov AR \& Astrup A 2004 Effect of normal-fat diets, either medium or high in protein, on body weight in overweight subjects: a randomised 1-year trial. International Journal of Obesity 28 1283-1290.

Erdmann J, Lippl F \& Schusdziarra V 2003 Differential effect of protein and fat on plasma ghrelin levels in man. Regulatory Peptides 116 101-107.

ErlansonAlbertsson C 2005 How palatable food disrupts appetite regulation. Basic and Clinical Pharmacology and Toxicology 97 61-73.

Espelund U, Hansen TK, Hojlund K, BeckNielsen H, Clausen JT, Hansen BS, Orskov H, Jorgensen JOL \& Frystyk J 2005 Fasting unmasks a strong inverse association between ghrelin and cortisol in serum: studies in obese and normal-weight subjects. Journal of Clinical Endocrinology and Metabolism $90741-746$.

Gibson E, Checkley S, Papadopoulos A, Poon L, Daley S \& Wardle J 1999 Increased salivary cortisol reliably induced by a protein-rich midday meal. Psychosomatic Medicine 61 214-224.

Golay A \& Bobbioni E 1997 The role of dietary fat in obesity. International Journal of Obesity 21 S2-S11.

Golay A, Eigenheer C, Morel Y, Kujawski P, Lehmann T \& Detonnac N 1996 Weight-loss with low or high carbohydrate diet? International Journal of Obesity 20 1067-1072.

Greenman Y, Golani N, Gilad S, Yaron M, Limor R \& Stern N 2004 Ghrelin secretion is modulated in a nutrient- and gender-specific manner. Clinical Endocrinology 60 382-388.

Halton TL \& Hu FB 2004 The effects of high protein diets on thermogenesis, satiety and weight loss: a critical review. Journal of the American College of Nutrition 23 373-385.

Havel PJ 2004 Update on adipocyte hormones - regulation of energy balance and carbohydrate/lipid metabolism. Diabetes $\mathbf{5 3}$ S143-S151.

James P 2004 Obesity: the worldwide epidemic. Clinics in Dermatology 22 276-280.
Jen KLC, Bodkin NL, Metzger BL \& Hansen BC 1985 Nutrient composition: effects on appetite in monkeys with oral factors held constant. Physiology and Behavior 34 655-659.

Johnston CS, Day CS \& Swan PD 2002 Postprandial thermogenesis is increased $100 \%$ on a high-protein, low-fat diet versus a high-carbohydrate, low-fat diet in healthy, young women. Journal of the American College of Nutrition 21 55-61.

Johnston CS, Tjonn SL \& Swan PD 2004 High-protein, low-fat diets are effective for weight loss and favorably alter biomarkers in healthy adults. Journal of Nutrition 134 586-591.

Kadowaki T \& Yamauchi T 2005 Adiponectin and adiponectin receptors. Endocrine Reviews 26 439-451.

Kamara K, Eskay R \& Castonguay T 1998 High-fat diets and stress responsivity. Physiology and Behavior 64 1-6.

Klein S 2004 Clinical trial experience with fat-restricted versus carbohydraterestricted weight-loss diets. Obesity Research 12 141S-144S.

Lacroix M, Gaudichon C, Martin A, Morens C, Mathe V, Tome D \& Huneau J 2004 A long-term high-protein diet markedly reduces adipose tissue without major side effects in Wistar male rats. American Journal of Physiology 287 R934-R942.

LaraCastro C \& Garvey WT 2004 Diet, insulin resistance, and obesity: zoning in on data for Atkins dieters living in South Beach. Journal of Clinical Endocrinology and Metabolism 89 4197-4205.

Legendre A \& Harris RB 2006 Exaggerated response to mild stress in rats fed high-fat diet. American Journal of Physiology 291 R1288-R1294.

Levin BE 2005 Factors promoting and ameliorating the development of obesity. Physiology and Behavior 86 633-639.

Levine AS, Kotz CM \& Gosnell BA 2003 Sugars: hedonic aspects, neuroregulation, and energy balance. American Journal of Clinical Nutrition 78 834S-842S

Lindqvist A, DornonvilledelaCour C, Stegmark A, Hakanson R \& ErlansonAlbertsson C 2005 Overeating of palatable food is associated with blunted leptin and ghrelin responses. Regulatory Peptides 130 123-132.

McAuley KA, Hopkins CM, Smith KJ, McLay RT, Williams SM, Taylor RW \& Mann JI 2005 Comparison of high-fat and high-protein diets with a high-carbohydrate diet in insulin-resistant obese women. Diabetologia $\mathbf{4 8}$ $8-16$.

Moesgaard SG, Ahren B, Carr RD, Gram DX, Brand CL \& Sundler F 2004 Effects of high-fat feeding and fasting on ghrelin expression in the mouse stomach. Regulatory Peptides 120 261-267.

Moran LJ, LuscombeMarsh ND, Noakes M, Wittert GA, Keogh JB \& Clifton PM 2005 The satiating effect of dietary protein is unrelated to postprandial ghrelin secretion. Journal of Clinical Endocrinology and Metabolism 90 5205-5211.

Morens C, Keijzer M, deVries K, Scheurink A \& vanDijk G 2005 Effects of high-fat diets with different carbohydrate-to-protein ratios on energy homeostasis in rats with impaired brain melanocortin receptor activity. American Journal of Physiology. Regulatory, Integrative and Comparative Physiology 289 R156-R163.

Ott V, Fasshauer M, Dalski A, Meier B, Perwitz N, Klein HH, Tschop M \& Klein J 2002 Direct peripheral effects of ghrelin include suppression of adiponectin expression. Hormone and Metabolic Research 34 640-645.

Otto B, Tschop M, Heldwein W, Pfeiffer AFH \& Diederich S 2004 Endogenous and exogenous glucocorticoids decrease plasma ghrelin in humans. European Journal of Endocrinology 151 113-117.

Pavlatos S, Kokkinos A, Tentolouris N, Doupis J, Kyriaki D \& Katsilambros N 2005 Acute effects of high-protein and high-fat isoenergetic meals on total ghrelin plasma concentrations in lean and obese women. Hormone and Metabolic Research 37 773-775.

Pecoraro N, Reyes F, Gomez F, Bhargava A \& Dallman MF 2004 Chronic stress promotes palatable feeding, which reduces signs of stress: feedforward and feedback effects of chronic stress. Endocrinology 145 3754-3762.

Pischon T, Girman CJ, Rifai N, Hotamisligil GS \& Rimm EB 2005 Association between dietary factors and plasma adiponectin concentrations in men. American Journal of Clinical Nutrition 81 780-786.

Prasad C, Delahoussaye AJ, Prasad A \& Mizuma H 1995 Augmentation of dietary fat preference by chronic, but not acute, hypercorticosteronemia. Life Sciences 56 1361-1371. 
Rabolli D \& Martin R 1977 Effects of diet composition on serum levels of insulin, thyroxine, triiodothyronine, growth hormone, and corticosterone in rats. Journal of Nutrition 107 1068-1074.

Reaven GM 2005 The insulin resistance syndrome: definition and dietary approaches to treatment. Annual Review of Nutrition 25 391-406.

Reid M \& Hetherington M 1997 Relative effects of carbohydrates and protein on satiety - a review of methodology. Neuroscience and Biobehavioral Reviews 21 295-308.

Sanchez J, Oliver P, Palou A \& Pico C 2004 The inhibition of gastric ghrelin production by food intake in rats is dependent on the type of macronutrient. Endocrinology 145 5049-5055.

Sclafani A 1987 Carbohydrate-induced hyperphagia and obesity in the rat: effects of saccharide type, form, and taste. Neuroscience and Biobehavioral Reviews 11 155-162.

Sclafani A, Lucas F \& Ackroff K 1996 The importance of taste and palatability in carbohydrate-induced overeating in rats. American Journal of Physiology 39 R1197-R1202.

SegalIsaacson CJ, Johnson S, Tomuta V, Cowell B \& Stein DT 2004 A randomized trial comparing low-fat and low-carbohydrate diets matched for energy and protein. Obesity Research $12130 \mathrm{~S}-140 \mathrm{~S}$.

Skov AR, Toubro S, Ronn B, Holm L \& Astrup A 1999 Randomized trial on protein versus carbohydrate in ad libitum fat reduced diet for the treatment of obesity. International Journal of Obesity 23 528-536.

Stern L, Iqbal N, Seshadri P, Chicano KL, Daily DA, McGrory J, Williams M, Gracely EJ \& Samaha FF 2004 The effects of low-carbohydrate versus conventional weight loss diets in severely obese adults: one-year follow-up of a randomized trial. Annals of Internal Medicine 140 778-785.

Strack A, Akana S, Horsley C \& Dallman M 1997 A hypercaloric load induces thermogenesis but inhibits stress responses in the SNS and HPA system. American Journal of Physiology 272 R840-R848.

Stricker-Krongrad A, Cumin F, Burlet C \& Beck B 1998 Hypothalamic neuropeptide $\mathrm{Y}$ and plasma leptin after long-term high-fat feeding in the rat. Neuroscience Letters 254 157-160.

Stubbs RJ 1995 Macronutrient effects on appetite. International Journal of Obesity 19 S11-S19.

Tannenbaum BM, Brindley DN, Tannenbaum GS, Dallman MF, McArthur MD \& Meaney MJ 1997 High-fat feeding alters both basal and stressinduced hypothalamic-pituitary-adrenal activity in the rat. American Journal of Physiology 36 E1168-E1177.
Tome D 2004 Protein, amino acids and the control of food intake. British Journal of Nutrition 92 S27-S30.

Tschop M, Smiley DL \& Heiman ML 2000 Ghrelin induces adiposity in rodents. Nature $407908-913$.

Tung YL, Hewson AK \& Dickson SL 2004 Glucocorticoid-dependent stimulation of adiposity and appetite by a ghrelin mimetic in the rat. European Journal of Endocrinology 150 905-911.

VallejoCremades MT, GomezGarcia L, ChacatasCortesao M, Moreno C, Sanchez M, DeMiguel E \& deSegura IAG 2004 Enriched protein dietmodified ghrelin expression and secretion in rats. Regulatory Peptides 121 113-119.

Warwick ZS \& Schiffman SS 1992 Role of dietary fat in calorie intake and weight gain. Neuroscience and Biobehavioral Reviews 16 585-596.

Weigle DS, Cummings DE, Newby PD, Breen PA, Frayo RS, Matthys CC, Callahan HS \& Purnell JQ 2003 Roles of leptin and ghrelin in the loss of body weight caused by a low fat, high carbohydrate diet. Journal of Clinical Endocrinology and Metabolism 88 1577-1586.

Weigle DS, Breen PA, Matthys CC, Callahan HS, Meeuws KE, Burden VR \& Purnell JQ 2005 A high-protein diet induces sustained reductions in appetite, ad libitum caloric intake, and body weight despite compensatory changes in diurnal plasma leptin and ghrelin concentrations. American Journal of Clinical Nutrition 82 41-48.

Wolever TMS 2003 Carbohydrate and the regulation of blood glucose and metabolism. Nutrition Reviews 61 S40-S48.

Yamauchi T, Kamon J, Waki H, Terauchi Y, Kubota N, Hara K, Mori Y, Ide T, Murakami K, Tsuboyama-Kasaoka N et al. 2001 The fat-derived hormone adiponectin reverses insulin resistance associated with both lipoatrophy and obesity. Nature Medicine 7 941-946.

Yancy WS, Olsen MK, Guyton JR, Bakst RP \& Westman EC 2004 A lowcarbohydrate, ketogenic diet versus a low-fat diet to treat obesity and hyperlipidemia - a randomized, controlled trial. Annals of Internal Medicine $140769-777$.

\section{Received in final form 12 October 2007 \\ Accepted 16 October 2007 \\ Made available online as an Accepted Preprint 16 October 2007}

